\title{
Islam dan Philosophia Perennis: Catatan atas Kritik Legenhausen Terhadap Philosophia Perennis Seyyed Hossein Nasr
}

\author{
Mulyani \\ Mahasiswa Pascasarjana IC-Paramadina, Jakarta. Anggota Lingkar Studi Islam dan Kebudayaan (LSIK), Ciputat
}

\begin{abstract}
The idea of Philosophia Perrennis Seyyed Hossein Nasr isn't detached from points of weakness, so Legenhausen gives critical notes on the Nasr thoughts. But, Legenhausen's critical note also isn't free from weakness too, so as its consequences, the public saw his critical notes is just defensively apologetic criticism of the Muslim orthodoxy. This paper tried to elaborate Legenhausen's critical view, so that orthodoxy of traditional Islam is still authoritative.
\end{abstract}

Kata Kunci: Legenhausen; Philosophia Perennis; Seyyed Hossein Nasr; Islam

\section{Pendahuluan}

Legenhausen melakukan kritik terhadap gagasan Philosophia Perrennis Seyyed Hossein Nasr, sebagaimana diakuinya, hal itu terdorong karena begi- tu besarnya pengaruh Nasr dalam pandangannya. Nasr, tanpa diragukan lagi, merupakan eksponen brilian dari pemikiran Islam di Barat. Dalam bangunan kritik Legenhausen terlihat beberapa kelemahan dalam penyusunan argumentasinya sehingga perlu dibaca secara kritis. Legenhausen telah berhasil meyakinkan bahwa dengan tetap berpegang pada eksklusifitas orto- doksi Islam tradisional, Muslim mampu bersikap toleran terhadap kenya- taan plural. Sikap percaya diri yang tinggi mendorong Legenhausen berke- simpulan bahwa tatanan ruang sosial Islam lebih mampu menciptakan tole- ransi ketimbang ruang publik Liberalisme Modernitas.

Secara garis besar, penulis setuju dengan arah kritikan Legenhausen, namun setidaknya terdapat dua poin sebagai celah kritik balik bagi Legenhasuen. Pertama, Legenhausen mengkritik Nasr yang tidak mengakui prinsip "Non- kontradiksi" ketika berupaya mendamaikan perbedaan-perbedaan diametral antar tradisi. Penulis melihat penjelasan Nasr bahwa prinsip Non-kontra- diksi tidak dapat diberlakukan ketika terdapat perbedaan level pemahaman, dapat diterima. Genealogi gagasan ini umum diketahui terdapat di dalam tradisi Sufism. Kedua, Legenhausen melihat genealogi dari Sophia Perrennis Nasr berasal dari tradisi okultasi romatisme Eropa. Kalaupun itu benar, maka tidak dapat dinafikan warna metafisika sufi di dalam gagasan Nasr, terutama terkait manifestasi dan kehendak Tuhan. Benar jika dikatakan Nasr memperluas jalan kebenaran kepada tradisi-tradisi keagamaan di luar Islam yang pada dasarnya asing dalam literature sufisme namun Nasr bisa saja berargumentasi bahwa itu semua merupakan ijtihad barunya dalam ma- salah tersebut. Untuk mengelaborasi dua poin ini, penulis bisa jadi sepakat dengan Nasr namun tetap menyelisihi kesimpulan akhir yang diajukannya.

\section{Philosophia Perennis Seyyed Hossein Nasr}

Definisi

Nasr menggunakan terma Philosophia Perennis atau Sophia Perennis untuk mendeskripsikan gagasannya tentang Pluralisme Agama. Kedua istilah tersebut digunakan secara bergantian karena meskipun berbeda namun memberi maksud yang 
Konfrontasi: Jurnal Kultur, Ekonomi dan Perubahan Sosial, 5 (1) January 2018, 1-7

P-ISSN: 1410-881X (Print)

Mulyani, Islam dan Philosophia Perennis: Catatan atas Kritik Legenhausen Terhadap

Philosophia Perennis Seyyed Hossein Nasr

DOI: -

http://www.konfrontasi.net/index.php/konfrontasi2

sama. Philosophia Perennis lebih menekankan dimensi intelektual sedangkan Sophia perennis pada dimensi pengalaman langsung namun keduanya menjelaskan kebenaran yang sama pada level transenden.

Mengikuti A.K.Coomaraswamy, Nasr mendefinisikan Philosophia Perennis sebagai pengetahuan tentang prinsip-prinsip universal yang terdapat di da- lam masyarakat yang memiliki keragaman klaim kebenaran dan sejarah yang berbeda. Pengetahuan yang menjadi inti dari seluruh agama ini dapat diraih melalui berbagai bentuk ritual dan metode dari berbagai tradisi mela- lui jalan pewahyuan.3 Tradisi keagamaan membentang dari agama semitik, agama-agama yang tumbuh di India, dan agama-agama tradisional seperti kepercayaan suku aborigin di Australia dan suku Indian di Amerika Utara.Semuanya diakui oleh Nasr sebagai tradisi keagamaan yang memiliki penda- saran pada pewahyuan.

Philosophia Perennis merupakan pengetahuan tentang realitas tertinggi nan suci (scientia sacra) yang bersifat metafisik, Jenis pengetahuan ini didapat dengan memfungsikan daya intelektus dan pengalaman mistik illuminatif. Pengetahuan tersebut berada pada inti semua agama. Karenanya, penge- tahuan ini (Sophia Perennis) memberi makna pada doktrin, ritus dan sim- bol-simbol suatu agama.5 Sophia perennis merupakan hikmah ketuhanan yang diakses oleh para petualang spiritual yang sudah sampai pada level tertentu.

Para Pendukung

Para pendukung gagasan philosophia perennis adalah figur-figur yang disebut oleh Nasr sebagai Tradisionalis. Beberapa nama yang disebutkan oleh Nasr diantaranya R. Guénon, A.K. Coomaraswamy, M.Pallis, T.Burck- hart, M.Lings, Lord Northbourne, L.Schaya, W.N.Perry, H.Smith dan F.Schuon. Para tradisionalis ini tersebar di dalam berbagai tradisi namun satu hal yang menyatukan mereka yaitu sikap mereka yang tidak membatasi diri pada level eksoterik namun melihat esensi agama pada level esoterik. Tradisionalis tetap mengakui ortodoksi namun memperluasnya ke level universal yaitu dengan memandang keanekaragaman fenomena keagamaan sebagai manifestasi yang beragam dari sifat-sifat Tuhan.

Genealogi

Jika kita perhatikan dari para tradisionalis yang disebutkan oleh Nasr di atas, umumnya mereka adalah para petualang spiritual yang benar-benar memasuki dan merasakan hidup di dalam tradisi agama. Beberapa di antaranya menjadi Muslim setelah perjalanan panjang menelusuri berbagai tradisi agama. Kesimpulan Legenhausen yang menyatakan bahwa gagasan para tradisionalis ini mengalir dari romantisme Eropa tidaklah sepenuhnya benar. Mekipun al-Attas sepakat dengan Legenhausen, namun al-Attas meli- hat pengaruh metafisika Islam yang cukup kuat pada para tradisionalis, multifarious dimensions has never been treated with such amplitude and depth as in the works of Schuon. The religious subjects dealt with by this school range from metaphysics and cosmology to sacred art with which they are especially concerned, and from traditional psychology and anthropology to ethics and social structure, for only through the sacred form can one reach the Formless. Lihat juga h. 32- 33.

Secara kasat mata juga tampak dari sikap sebagian tradisonalis yang merasa perlu untuk menampakkan keislamannya bahkan mengubah-ubah identitas (seperti: nama dan gaya hidup) sebelumnya.8 Oleh karena itu, jika benar adanya pengaruh romantisme Eropa atau filsafat dan sains modern, menu- rut al-Attas, tetap saja pengaruh metafisika Islam terlihat lebih mewarnai berbagai konsepsi mereka. 
Konfrontasi: Jurnal Kultur, Ekonomi dan Perubahan Sosial, 5 (1) January 2018, 1-7

P-ISSN: 1410-881X (Print)

Mulyani, Islam dan Philosophia Perennis: Catatan atas Kritik Legenhausen Terhadap

Philosophia Perennis Seyyed Hossein Nasr

DOI: -

http://www.konfrontasi.net/index.php/konfrontasi2

\section{Posisi Legenhausen Terhadap Philosophia Perennis}

Nasr

Langkah pertama Legenhausen dalam mengkritik pandangan Sophia perenis Nasr adalah dengan membuat pemisahan antara dimensi Deontis, Aletis dan Soteriologis agama menurut Islam. Islam bersifat ekslusif ketika menegaskan bahwa agama yang benar adalah agama yang diturunkan Allah kepada utusan terakhir-Nya yaitu nabi Muhammad SAW. Islam tidak meng- ingkari kenabian sebelum Muhammad sehingga agama yang diturunkan Allah kepada nabi-nabi sebelumnya tetap sah sampai kedatangan Muhammad. Oleh karena itu, Islam mengakui adanya bentuk pluralisme agama yang bersifat deontik diachronic, dimana ada banyak agama atau lebih tepatnya syariah yang diturunkan Allah kepada para nabi namun kebenaran- nya bersifat suksesif berdasarkan periode kenabiannya masing-masing.9 Setelah kedatangan Muhammad, hanya Islam Muhammadan yang benar dan diakui oleh Allah.10 Ketika Islam bersikap ekslusif atas kebenaran yang dikandungnya bukan berarti keselamatan secara mutlak hanya diperuntuk- kan bagi Muslim. Masih ada kemungkinan orang-orang di luar Islam untuk mendapatkan keselamatan. Dengan menjelaskannya secara semantik, Legenhausen ingin menyatakan bahwa Kekafiran yang menyelubungi diri seseorang dari kebenaran merupakan sikap sadar dan bersifat aktif. Keku- furan merupakan sikap pilihan bebas seseorang untuk tetap berada di dalam kesalahan. Kenyataan itu bukan keinginan Tuhan namun kecongkakan manusia itu sendiri. Oleh sebab itu mengkaitkan dan mencampuradukkan antara keadilan Tuhan, keragaman agama, doktrin keselamatan dan persoalan toleransi menjadi tidak relevan.

\section{Analisis Kritis Terhadap Beberapa Point Kritikan Legenhausen}

Pengabaian Prinsip Non-Kontradiksi

Terbentuknya agama-agama dilihat oleh Nasr sebagai kehendak dan rencana Tuhan. Nasr melihatnya sebagai wahyu, bukan penemuan manusia. Karena- nya bagi Nasr tidak perlu ada reformasi pada level tersebut. Meskipun peru- bahan dalam tradisi keagamaan dapat terjadi secara bertahap, organik dan natural, namun tidak ada perubahan hukum-hukum abadi Tuhan yang ter- dapat di dalam masing-masing tradisi keagamaan. Reformasi bagi Nasr hanya perlu dilakukan untuk memperluas makna absolut kalangan ekslusifis dari masingmasing tradisi.12 Nasr dilihat oleh Legenhausen tidak mela- kukan pemisahan secara tegas antara aspek keabadian hukum Tuhan de- ngan aspek-aspek dimana agama mengalami perubahan organik dan natu- ral. Nasr hanya memberi jawaban tidak langsung dengan menegaskan bahwa Tuhan tidak akan membiarkan agama-agama besar berada di dalam kesa- lahan sampai ribuan tahun. Nasr menyatakan:

How could God allow, with his infinite wisdom and justice, one of the of major religions of people have sought their salvation, to be misguided for two thousand years? Was this simply mistake?... if one says that this was all horrendous mistake for this thousand years, I cannot accept this.

Oleh karena itu kalaulah benar apa yang termaktub di dalam dokumen- dokumen sejarah bahwa yesus dan generasi Kristen awal tidaklah menga- jarkan doktrin trinitas dan inkarnasi, namun doktrin tersebut dikehendaki oleh Tuhan bagi generasi Kristen berikutnya, tegas Nasr.14 Kehendak Tuhan, di dalam konsepsi Nasr, memanifestasikan dirinya dalam beragam bentuk di dalam bentangan sejarah yang nampak ke permukaan sebagai tradisi 
Konfrontasi: Jurnal Kultur, Ekonomi dan Perubahan Sosial, 5 (1) January 2018, 1-7

P-ISSN: 1410-881X (Print)

Mulyani, Islam dan Philosophia Perennis: Catatan atas Kritik Legenhausen Terhadap

Philosophia Perennis Seyyed Hossein Nasr

DOI: -

http://www.konfrontasi.net/index.php/konfrontasi2

keaga- maan yang berbedabeda. Namun karena wujudnya merupakan hasil dari manifetasi kehendak Tuhan maka semuanya valid.15 Nasr menolak pandang- an nonrelatifistik yang dianut secara tradisional. Legenhausen mengkritik- nya dengan menyatakan bukanlah kesalahan Tuhan untuk membiarkan definitions pertaining to issues concerning how non-muslims are to be treated according to Islamic law, while the question of salvation pertains to the inner state of the individual. The literal meaning of infidelity (kufr) is covering. The infidel is one who seeks to shield or cover himself from the truth of islam. Infidelity is not passive condition applying to all those who lack correct belief in islam, rather it is in active inward opposition which prevent a person from accepting divine guidance." suatu tradisi tetap dalam kesalahan, jika memang kesalahan tersebut meru- pakan kesalahan manusia itu sendiri (lihat; penjelasan Legenhausen tentang makna kufur secara semantik di atas).

Di sinilah kemudian berdasarkan teorinya tentang manifestasi kehendak Tuhan, Nasr mengingkari prinsip non-kontradiksi. Sebagai contoh, Islam dan Kristen memiliki narasi yang berbeda (kontradiksi) dalam melihat figur Yesus, namun keduanya oleh Nasr dianggap valid. Nasr sendiri menyatakan bahwa hal ini sangat sulit dipahami dengan kacamata rasionalitas.16 Perbedaan perspektif dan level pemahamanlah yang akan dapat menye- lesaikan kontradiksi tersebut.17 Namun Legenhausen kemudian memper-soalkan argumentasi Nasr tersebut ketika Nasr tidak menjelaskan bagai- mana Yesus disalib pada satu level dan tidak pada level lainnya. Nasr hanya menyatakan hanya para pemikir yang mencapai kematangan tertentulah yang mampu memahami gagasannya tersebut.18

Pengakuan atas prinsip non-kontradiksi menjadi aksioma fundamental bagi bangunan logika. Instrumen logika menjadi perangkat metodik untuk menguji apakah suatu pikiran dapat dikatakan benar. Instrument logika (mantiq) digunakan oleh para filosuf dan mutakallimin namun diposisikan secara unik dalam tradisi tasawwuf 'irfan. Artinya para sufi commit untuk menampilkan kesadaran mistik iluminatif mereka menggunakan terma- terma logika (ushuli), namun konten kognitif pengalaman itu sendiri musta- hil dimuat dalam wacana filsafat. Di samping itu pengetahuan langsung (hudhuri) lebih kaya dari pengetahuan 'aqliyah dan di dalamnya prinsip- prinsip logika terkadang tidak lagi berlaku. Karenanya, kesadaran gnosis sufi melampaui terma-terma logis.

Di dalam risalah-risalah sufi banyak ditemukan kisah perjalanan spiritual Musa bersama khidir.19 Para sufi menempatkan Musa berada pada level spiritual (Maqamat) yang berbeda dengan Khidir. Khidir telah dikaruniai 'ilm laduni sedangkan Musa tidak. Perjalanan Musa bersama Khidir digam- barkan oleh salah seorang sufi Fariz bin Isa alDinawari al-Baghdadi (w.951), sebagaimana dikutip Kristin Zahra Sands berikut:

"Musa said , "god willing" about himself in "You will find me patient, God willing," but al-Khidir did not do the same when he said, "You will not be able to be patient with me," because the knowledge of Musa at that time was the knowledge of what religious law has prescribed and deduction (istidlal), but the knowledge of al-Khidir was God-given knowledge ('ilm laduni) from one unseen to another. Musa was in the station (maqam) of learning properbehavior (ta'dib) while al-Khidir was in station (maqam) of unveiling (kashaf) and witnessing (mushahada)."

Di dalam perjalanan ini, Musa mengalami banyak kesulitan dan tidak mam- pu memahami tindakan-tindakan Khidir yang terlihat baginya keliru lagi menyelisihi aturan Tuhan. Namun pada kenyataannya, keterbatasan penge- tahuan Musa lah yang menyebabkan ia tidak mampu memahami Khidir. Khidir tampak oleh Musa menyelisihi hukum Tuhan 
Konfrontasi: Jurnal Kultur, Ekonomi dan Perubahan Sosial, 5 (1) January 2018, 1-7

P-ISSN: 1410-881X (Print)

Mulyani, Islam dan Philosophia Perennis: Catatan atas Kritik Legenhausen Terhadap

Philosophia Perennis Seyyed Hossein Nasr

DOI: -

http://www.konfrontasi.net/index.php/konfrontasi2

sehingga menyimpan kontradiksi, namun jika ilmu Khidir diraih oleh Musa, kontradiksi tersebut tidak lagi tampak. Begitulah tradisi sufi menafsirkan kisah perjalanan Khidir dan Musa. Oleh karenaitu tidak heranjika Nasr seolah ingin melakukan hal yang sama terhadap berbagai pihak yang tidak memahami gagasannya.

Spekulasi Filosofis dan Philosophia Perennis Nasr

Legenhausen memandang gagasan Philosophia Perennis Nasr sangat asing dalam tradisi intelektul Islam. Legenhasuen berupaya membuktikan bahwa gagasan Nasr tidak mendapat dukungan dari para filosof, ahli kalam dan sufi. Ketika Nasr melihat perbedaan eskatologis agama-agama bersifat valid, sepanjang itu pula hanya berlaku di dalam alam spiritualnya masing- masing.21 Nasr kemudian menjustifikasinya dengan pandangan sufi tradisi- onal terutama Jalaluddin Rumi dan Ibn Arabi.

Namun Legenhausen menyimpulkan bahwa pandangan Nasr tentang plural- isme agama tidak dapat dipertahankan sekaligus tidak sesuai dengan pandangan mayoritas sarjana Muslim tradisional.

Ketika Maulana Jalaluddin Rumi bersyair "lampu-lampu itu berbeda namun cahayanya tetap sama", bukan berarti Maulana membenarkan pandangan para pluralis, tegas Legenhausen. Apa yang dimaksud oleh sang Maulana sama seperti yang sampaikan oleh Qur'an bahwa lampu-lampu yang berbeda adalah cahaya Islam melalui Nubuwah yang diturunkan secara suksesif oleh Allah berdasarkan periodenya masing-masing.24 Hal itu terlihat jelas dari penolakan Rumi terhadap sikap status quo al-Jannah terhadap iman kris- tennya. Rumi mengatakan:

"This is not the action or the words on an intelligent man possessed of sound. God gave you intelligence of your own other than your father's intelligence, asight of your own other than your father's sight, a discri- mination of your own. Why you nullify your sight and your intelligence, following an intelligence which will destroy you and not guide you?."

Rumi menambahkan "Anjing saja tidak lagi mengikuti induknya mengais- ngais sampah setelah dilatih oleh seorang raja. Sangat ironis ketika manusia dengan kemampuan akalnya tidak mampu lebih baik dari itu." Selain Rumi, Ibn Arabi juga melakukan hal yang sama. ketika ditanya bagaimana memperlakukan pengikut kristiani. Ibn Arabi menjawabnya sesuai dengan ketentuan hukum Islam. Umat Kristen bagi Ibn 'Arabi seharusnya mengikuti syariah Islam yang diturunkan kepada nabi Muham- mad. Itu artinya syariat nabi sebelumnya ditanggalkan setelah turunnya al- Qur'an. Jelaslah bahwa Islam merupakan satu-satunya agama yang valid setelah diutusnya Rasulullah SAW sebagai nabi penutup yang menyem- purnakan seluruh ajaran para nabi sebelumnya.

Benar jika dikatakan bahwa agama terdiri dari dimensi lahir (zahir) dan dimensi batin (bathin) dimana yang satu berbeda dari yang lainnya. Para sufi melihat perbedaan banyak muncul pada dimensi lahir dari agama namun dimensi batinnya sama. Oleh karena itu, para sufi lebih memfokus- kan pada dimensi batin agama, dengan tidak mengabaikan dimensi lahirnya. Mayoritas sufi secara tegas telah menyeru untuk mengikuti ketentuan-ketentuan hukum Islam. Masyhur di kalangan sufi pernyataan bahwa tidak ada thariqah tanpa syari'ah.

Setelah membuktikan bahwa Nasr sejatinya tidak mendapat dukungan dari khazanah sufi tradisional, Legenhausen beranjak membahas secara sepintas pandangan para filosof 
Konfrontasi: Jurnal Kultur, Ekonomi dan Perubahan Sosial, 5 (1) January 2018, 1-7

P-ISSN: 1410-881X (Print)

Mulyani, Islam dan Philosophia Perennis: Catatan atas Kritik Legenhausen Terhadap

Philosophia Perennis Seyyed Hossein Nasr

DOI: -

http://www.konfrontasi.net/index.php/konfrontasi2

Muslim. Hasil penelusurannya menyimpulkan tidak ada perbedaan di antara keduanya dalam membahas tema ini. Baik sufi maupun filosof, semuanya sepakat bahwa satusatunya agama yang dike- hendaki oleh Tuhan adalah Islam. Perbedaan di antara sufi dan filosof hanyalah dari cara mereka memahami unsur batin dari agama-agama wahyu. Yang satu mendekatinya dengan penyingkapan langsung melalui penyucian jiwa, sedangkan yang lain melalui argumentasi filosofis.28 Jika sufi dan filosof menegaskan satu-satunya agama yang valid hanya Islam, terlebih lagi tradisi para teolog Muslim. Pandangan nasr dipastikan oleh legenhausen tidak didukung oleh khazanah intelektual Islam, baik dari kajian teologi, tasawuf dan filsafat.29 Lebih jauh Legenhausen menyatakan:

"The basis for modern perspective defended by Nasr is insight into eso- teric dimentions of religions of the world, but it remains a human insight and speculation. The basis for the persfective internal to Islam, on the other hand, is divine revelation."30

Kesimpulan Legenhausen bahwa gagasan Philosophia Perennis Nasr meru- pakan spekulasi pikiran manusia semata perlu dipertanyakan, karena Nasr sendiri di banyak tempat menyatakan bahwa Sophia Perennis bukan hanya mengandalkan pemikiran rasional, namun (seperti halnya tradisi sufi) juga berasal dari limpahan langsung dari Tuhan. Itu Nampak dari kutipan berikut:

"Although theoretically it is possible for man to gain this knowledge, at least on a more outward level, by himself because of the nature of the intellect, that "supernaturally natural" faculty which is ingrained in the very substance of man, the norm is such that the attainment of this knowledge depends upon the grace and the framework which tradition alone provides. If there are exceptions, they are there to prove the rule and bear witness to the well-known dictum that "the Spirit bloweth where it listeth."

Tampak jelas juga ketika Nasr mendefinisikan realitas agama. Agama bukan hanya seperangkat keyakinan namun merupakan realitas bersumber dari dimensi ketuhanan.32 Agama bagi Nasr memiliki fungsi sentral dalam diri manusia, dimana manusia melalui agama dapat melakukan perjalanan pan- jang untuk memahami realitas eksistensial kehidupan. Agama bukan hanya memberi jalan untuk memahami alam raya ini, namun lebih jauh lagi agama bertindak sebagai instrumen dalam memahami hakikat eksistensi kehidupan yang lebih fundamental dan nyata.33 Nasr juga menyatakan, agama ketika masih berada pada akal Tuhan yang berbentuk realitas archetypal, agama bersifat trans-historis.34 Sifat transhistoris agama tetap terkandung pada level esoteris. Meski pada tataran eksoterik, agama dapat mengalami perubahan yang bersifat organik natural, namun kemungkinan perubahan tersebut tidaklah merendahkan dimensi eksoteris agama. Doktrin, ritual, dan hukum-hukum legal agama tetap kudus sepanjang berada di dalam tradisinya masingmasing.

Ketika Legenhausen menyatakan"Perhaps the source of the pluralism defended by Dr. Nasr is not to be found in the sufi tradition at all, but in European romantic tradition as it survived in the twentieth century among the connoisseurs of the occult in Paris."35 Kita patut bertanya sejauh mana pengaruh itu atau tepatnya pada wilayah apa? Setidaknya berharap Legenhausen membuat kesimpulan tersebut tanpa menutup mata akan pengaruh kuat metafisika sufi tradisional atas Nasr.36 Jika kritik Legenhausen dikarenakan unsur relativisme yang merasuk ke dalam pikiran Nasr, sebagaimana ia menyebutnya "relativitas komunal", bukan berarti Nasr tidak memiliki limit of truth. Meskipun mengakui fenomena terbentuknya 
Konfrontasi: Jurnal Kultur, Ekonomi dan Perubahan Sosial, 5 (1) January 2018, 1-7

P-ISSN: 1410-881X (Print)

Mulyani, Islam dan Philosophia Perennis: Catatan atas Kritik Legenhausen Terhadap

Philosophia Perennis Seyyed Hossein Nasr

DOI: -

http://www.konfrontasi.net/index.php/konfrontasi2

berbagai tradisi keagamaan berasal dari manifestasi ketuhanan, bukan berarti para tradisionalis sama sekali tidak memiliki limit of truth. Mereka bukan hanya dapat melihat derajatderajat kebenaran, namun juga dapat membedakan antara sesuatu yang benar dengan sesuatu yang keliru, yang benar-benar agama dengan agama palsu. Artinya, mereka memiliki penge- tahuan dan sikap yang jelas terhadap fenomena keberagamaan tertentu tanpa terjatuh ke dalam sikap dogmatism di satu sisi dan relativisme di sisi lain, tegas Nasr.

\section{Kesimpulan}

Meski penulis tidak sepakat dengan gagasan Sophia Perennis Nasr, namun memberi catatan kritis pada Legenhausen perlu dilakukan khususnya dua point di atas. Catatan kritis tersebut diberikan agar dapat membaca Nasr serigit mungkin, demi bersikap adil terhadap Nasr dan pemeliharaan tradisi akurasi akademik yang sehat.

\section{Bibliografi}

Aslan, Adnan, Religious Pluralism in Cristian and Islamic Philosophy; the thought of John Hick and Seyyed Hossein Nasr (Britain and Japan: Curzon Press Ltd and Japan Library, 1994), cetakan pertama.

Sands, Kristin Zahra, Sufi Commentaries on the Qur'an in Classical Islam

(London and New York: Routledge, 2006).

Legenhausen, Muhammad, Islam and Religious Pluralism (Great Britain: Islamic Studies Department; Center for international Cultural Studies, 1999).

Nasr, Seyyed Hossein, The Need For Sacred Science (United Kingdom: Curzon Press Ltd, 1993), cet. I. 